$$
\text { Pontifícia } \text { Universidade }_{\text {Do Rio de Janeiro }}
$$

Anna Lee Rosa de Freitas

\title{
A missa bárbara rezada por Glauber Rocha num tempo que era proibido proibir
}

Tese de Doutorado

Tese apresentada ao Programa de PósGraduação em Letras da PUC-Rio como requisito parcial para obtenção do título de Doutor em Letras.

Orientador: Profa. Marília Rothier Cardoso Co-orientador: Profa. Ana Paula Veiga Kiffer 


$$
\text { Pontifícia } \text { Universidade }_{\text {Do Rio de Janeiro }}
$$

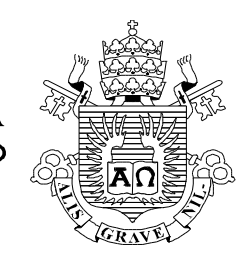

Anna Lee Rosa de Freitas

\begin{abstract}
A missa bárbara rezada por Glauber Rocha num tempo que era proibido proibir

Tese apresentada como requisito parcial para obtenção do grau de Doutor pelo Programa de Pós-Graduação em Letras do Departamento de Letras do Centro de Teologia e Ciências Humanas da PUC-Rio. Aprovada pela Comissão Examinadora abaixo assinada.
\end{abstract}

Profa. Marília Rothier Cardoso Orientadora Departamento de Letras - PUC-Rio

Profa. Ana Paula Veiga Kiffer

Co-Orientadora Departamento de Letras - PUC-Rio

Profa. Andrea França Martins Departamento de Comunicação Social - PUC-Rio

Profa. Josette Maria Alves de Souza Monzani Universidade Federal de São Carlos - UFSCAR

Prof. Jorge Luiz Rocha de Vasconcellos UFF

Prof. Paulo Guilherme Domenech Oneto UFRJ

Profa. Denise Berruezo Portinari Coordenadora Setorial do Centro de Teologia e Ciências Humanas - PUC-Rio

Rio de Janeiro, 14 de abril de 2011. 
Todos os direitos reservados. É proibida a reprodução total ou parcial do trabalho sem autorização da universidade, da autora e da orientadora.

\section{Anna Lee Rosa de Freitas}

Graduou-se em Comunicação Social/Jornalismo pela Faculdade da Cidade (1997). Possui Mestrado em Letras pela Pontifícia Universidade Católica do Rio de Janeiro (2007). Fez estágio doutoral na Sorbonne Nouvelle - Paris III (2009-2010) (Bolsa Sanduíche Capes). Atualmente é Pesquisadora de Texto da Rede Globo de Televisão; atuou como repórter/colunista no jornal Folha de S. Paulo e editora-assistente da Editora Globo. É escritora com vários livros publicados, sendo que, com $O$ beijo $d a$ morte, ganhou o Prêmio Jabuti de Reportagem em 2004. Ainda atua como revisora de tradução, copidesque e revisora técnica, e também como pesquisadora para livros diversos e exposições culturais.

Ficha Catalográfica

Freitas, Anna Lee Rosa de

A missa bárbara rezada por Glauber Rocha num tempo que era proibido proibir / Anna Lee Rosa de Freitas ; orientador: Marília Rothier Cardoso ; coorientador: Ana Paula Veiga Kiffer. 2011.

186 f. : il. (color.) ; $30 \mathrm{~cm}$

Tese (doutorado)-Pontifícia Universidade Católica do Rio de Janeiro, Departamento de Letras, 2011.

Inclui bibliografia

1. Letras - Teses. 2. Política. 3. Cinema. 4. Maio de 68 francês. 5. Imaginação. 6. Deleuze. I. Cardoso, Marília Rothier. II. Kiffer, Ana Paula Veiga III. Pontifícia Universidade Católica do Rio de Janeiro. Departamento de Letras. IV. Título. 
Para Edgard - meu irmão amado, que é mais do que isso: é melhor amigo, companheiro, cúmplice, confidente, conselheiro sem quem eu não teria chegado até aqui. 


\section{Agradecimentos}

Agradecimento especial:

À Marília Rothier Cardoso, minha orientadora.

Costumo dizer que a Marília me ensinou o caminho do Tempo Glauber. Na verdade, ela fez bem mais que isso. Quando chegamos lá, ela me iniciou nos ritos mágicos (que tanto conhece) necessários para participar da Missa Bárbara rezada por Glauber. Ao ajoelharmos para rezar, Marília me deu o conselho que tornou possível a escrita desta tese:

"Arrisque-se!"

Por toda e tanta generosidade, deixo registrado aqui meu eterno agradecimento.

À Jacqueline Penjon, minha orientadora na Paris III - Sorbonne Nouvelle, pela acolhida calorosa e incentivo, que se transformaram em amizade.

À Ana Paula Kiffer, minha co-orientadora, pelas portas do universo artaudiano que me abriu.

Ao Jorge Vasconcellos, amigo querido, pelas orientações, conversas deleuzianas, trocas de ideias, filmes e copos. 
Ao Paulo Oneto pelas reflexões sobre engajamento.

À Josette Monzani e à Andréa França pela disponibilidade e gentileza de participarem da banca.

Ao Tempo Glauber, especialmente D. Lúcia, Paloma, Ana Lúcia, Anna Karinne, João e Sara, pela disponibilidade e pela acolhida sempre carinhosa.

Ao Cony, por ter me inspirado e apoiado em meus percursos literários.

Ao querido amigo Sérgio Barcellos, desbravador de caminhos e guia.

A La Banda, especialmente, a Ruben e Miguel, por toda rebeldia e alegria que trazem para minha vida.

À Ju Coelho, pelo primeiro abraço parisiense, que se tornou amizade para a vida toda.

Às seis meninas, Bru, ma petite soeur, Aninha, Van, Tati, Laura e Nina, que deixaram minha temporada parisiense mais feliz e aquecida.

Ao Júlio Diniz, o Julinho, querido amigo de letras, livros e bares.

Ao Felipe, pela amizade e pelos exemplos mágicos.

A Dê Schittine, Myrtes, Miguel, Mariana Patrício, Mariano, Lucas, Christian, Domingos, Daniel - companheiros de caminhada e inquietações.

Aos funcionários do Departamento de Letras, especialmente, à querida Chiquinha, dona de todas as respostas.

À Capes e à PUC- Rio, pelos auxílios concedidos e, principalmente, pela bolsa PDEE em Paris, sem a qual este trabalho não poderia ter sido realizado. 


\section{Resumo}

Freitas, Anna Lee Rosa de; Cardoso, Marília Rothier. A missa bárbara rezada por Glauber Rocha num tempo que era proibido proibir. Rio de Janeiro, 2011. 186p. Tese de Doutorado - Departamento de Letras, Pontifícia Universidade Católica do Rio de Janeiro.

O Maio de 68 francês foi um movimento que propôs nova maneira de pensar o poder, segundo a qual não haveria mais distinção entre arte, saber e política, representando dessa forma o acontecimento da crise em toda sua potência, como espaço de imaginação e de criação. O cineasta brasileiro Glauber Rocha trabalha em afinidade com esta proposta, questionando esteticamente as instituições clássicas: ele põe em cena uma câmara em transe e personagens que explicitam a crise em seus discursos. Observa-se como os filmes de Glauber, representados neste ensaio por Terra em transe, Câncer e $A$ idade da terra, ao apresentarem episódios desalinhados, desordenados, incongruentes, arrebentam com as formas tradicionais de contar uma história. Tal explosão da linguagem cinematográfica clássica, presente no imaginário coletivo, arranca o público de sua posição passiva de espectador, convidando-o a uma experiência transformadora. E é nesse processo de desestruturação que Glauber, utilizando dinamismos espaços-temporais, se articula com a prática filosófica dos movimentos antiautoritários do Maio francês e do pós-68. Desenvolvido e divulgado no âmago do embate crítico, o pensamento do filósofo francês Gilles Deleuze constitui o fundamento teórico que sustenta esta experiência de leitura da performance de uma revolta popular em contraponto com a construção da artepensamento de um cineasta.

\section{Palavras-chave}

Política; cinema; Maio de 68 francês; imaginação; Deleuze. 


\section{Résumé}

Freitas, Anna Lee Rosa de; Cardoso, Marília Rothier. La messe célébrée par Glauber Rocha dans un temps où il était interdit d'interdire . Rio de Janeiro, 2011. 186p. Tese de Doutorado - Departamento de Letras, Pontifícia Universidade Católica do Rio de Janeiro.

Mai 68 a été un mouvement qui a proposé une nouvelle manière de penser le pouvoir politique, selon laquelle, il n'y aurait pas de distinction entre art et politique, représentant ainsi l'événement de la crise dans toute sa puissance, de la crise comme lieu d'imagination et de création. Le cinéaste brésilien Glauber Rocha utilise esthétiquement cette proposition soulignant la crise des institutions traditionnelles : il met en scène une caméra dans un état de transe et des personnages qui explicitent cette crise dans leurs discours. Ainsi, notre intention est de montrer comment Glauber dans ses films, représentés ici par Terre en transe, Câncer et L'âge de la terre, avec des scènes sans logique, non-ordonnées, incohérentes, bouleverse les manières traditionnelles de raconter une histoire. Il fait exploser le langage cinématographique classique, présent dans l'imaginaire collectif, et arrache le public à sa position de spectateur passif, l'invitant à une expérience de l'imagination. Et c'est dans ce processus de déstructuration que Glauber, employant dynamismes d'espace et de temps, s'articule avec la pratique philosophique des mouvements contre l'autoritarisme du Mai 68 et post cette époque, étant le fondement théorique qui soutient cette thèse est la pensée du philosophe français Gilles Deleuze.

\section{Mots clés}

Politique; cinema; imagination; Mai 68 français; Deleuze. 


\section{Sumário}

Introdução 12

Décor 36

1. Scène 1 - A revolução é uma eztetyka 47

2. Scène 2 - Entre o todo de Eisenstein e a fissura de Artaud: 71 o transe de Glauber Rocha

3. Scène 3 - O tecido fílmico e teatral esgarçado 90 pelo câncer e pela peste

4. Scène 4 - A tela glauberiana como um corpo sem órgãos 102

5. Scène 5 - Glauber, le Mômo 118

6. Scène 6 - Uma missa bárbara para acabar com o julgamento de deus

7. Post-scriptum

8. Referências Bibliográficas 


\section{Lista de Figuras}

Figura 1- La revolte, Le Magazine Littéraire Hors-série $N^{0} 13$, p.6

Figura 2- Livro: "Mai 68 d'um photographe" - Paris: Éditions Du Layeur, 2008, p. 106. Autor: Elie Kagan

Figura 3- Cartaz de divulgação do filme Before the Revolution /Prima della rivoluzione, Bernardo Bertolucci, 1964. Montreal showing

Figura 4- Cartaz de divulgação do filme La Chinoise, de Jean -Luc Godard

Figura 5- Cartaz de divulgação da exibição do filme Terra em Transe, de Glauber Rocha, No Tela Tudo Clube de Cinema (Cine SESI Pajuçara)

Figura 6- Affiches - mai -68 - greve - 1968 - pôster - 08 http://www.pageblanche-leblogdesseniors.com/ 2011/03/archives-seniores/affiches-mai-68-greve1968-poster-08-2/

Figura 7- Revista: Télérama - hors/série - "Mai 68 L'héritage", p. 78

Figura 8- Livro: "L'imagination au pouvoir. Photografies de Jo Schnapp", editora: Paris, Eric Losfeld, 1968

Figura 9- Revista: Télérama - hors/série - "Mai 68 L'héritage", p. 10

Figura 10- Livro: "Nous l'avons tant aimée, la révoluct ion"; autor: Dany Cohn-Bendit; editora: Éditions Bernard Barrault, 1986, p. 11

Figura 11- Revista: Télérama - hors/série - "Mai 68 L'héritage", p. 52

Figura 12- Livro: "68: Destinos. Passeata dos Cem Mil"; autor Evandro Teixeira; Editora Textual

Figura 13- Livro:" The Hog Farm and Friends"; autor:

Wavy Gravy; editora: Links Book, 1974 
Figura 14- Disponível em: http://www.imagem.ufri.br/index. php?acao $=$ detalharimagem\&idimg $=419$

Figura 15- Revista: Télérama - hors/série - "Mai 68 L'héritage", p. 49 